\title{
Laboreal
}

Volume $3 \mathrm{~N}^{\circ} 1$ | 2007

Varia

\section{Por las hendiduras del trabajo vivo : textos, contextos y actos en la actividad de vigilancia en salud del trabajador}

Pelas fendas do trabalho vivo : textos, contextos e atos na atividade de vigilância em saúde do trabalhador

Par les failles du travail vivant : textes, contextes et actes dans l'activité du préventeur en santé du travailleur

Through the gaps of living work : texts, contexts and acts in the activity of workers' health surveillance

\section{Kátia Santorum}

\section{OpenEdition}

\section{Journals}

\section{Edición electrónica}

URL: http://journals.openedition.org/laboreal/12934

DOI: $10.4000 /$ laboreal. 12934

ISSN: 1646-5237

\section{Editor}

Universidade do Porto

Referencia electrónica

Kátia Santorum, «Por las hendiduras del trabajo vivo : textos, contextos y actos en la actividad de vigilancia en salud del trabajador », Laboreal [En línea], Volume 3 Nº1 | 2007, Publicado el 01 julio 2009, consultado el 24 septiembre 2020. URL : http://journals.openedition.org/laboreal/12934 ; DOI : https://doi.org/10.4000/laboreal.12934

Este documento fue generado automáticamente el 24 septiembre 2020

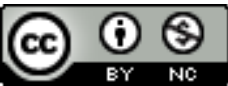

Laboreal está licenciado com uma Licença Creative Commons - Atribuição-NãoComercial 4.0 Internacional. 


\section{Por las hendiduras del trabajo vivo : textos, contextos y actos en la actividad de vigilancia en salud del trabajador}

Pelas fendas do trabalho vivo : textos, contextos e atos na atividade de vigilância em saúde do trabalhador

Par les failles du travail vivant : textes, contextes et actes dans l'activité du préventeur en santé du travailleur

Through the gaps of living work : texts, contexts and acts in the activity of workers' health surveillance

\section{Kátia Santorum}

\section{REFERENCIA}

Santorum, Katia. (2006). Pelas Fendas do Trabalho Vivo : textos, contextos e atos na atividade de Vigilância em Saúde do Trabalhador. Tese de Doutoramento. Rio de Janeiro : Escola Nacional de Saúde Pública Sérgio Arouca (ENSP) Fundação Oswaldo Cruz (FIOCRUZ)

\section{NOTA DEL EDITOR}

Manuscrito recibido en : febrero/2007

Aceptado tras peritage en : junio/2007 


\section{Introducción}

Las reflexiones aquí presentadas transcurren de la pesquisa de doctorado que contó con la orientación de la Investigadora Jussara Brito, de la ENSP. Tuvo como objetivo principal el análisis de la actividad de Vigilancia en Salud del Trabajador (VST), en el ámbito del Sistema Único de Salud (SUS) brasileño. El origen de este estudio se sitúa en la percepción de una discontinuidad entre las acciones en el campo de la salud del trabajador y los principios que le orientan. Entre los conocimientos acumulados y reflexiones sobre esas acciones de un lado y, de otro, los desdoblamientos que la vida de cada día solicita de aquellos y de aquellas que son responsables por ejecutarlas.

A pesar de los avances técnicos, políticos y legales, hay impases y atravesamientos en el camino surcado por esa política pública, a lo largo de la implementación de la Salud del Trabajador en el SUS. La dinámica de confrontaciones que marca su recorrido apunta para la necesidad de crear dispositivos que contribuyan para la legitimación e institucionalización de ese campo de prácticas. Así, la Vigilancia en Salud del Trabajador fue elegida como tema de la pesquisa, por la función estratégica que desempeña en la búsqueda de una relación sana de la sociedad con el trabajo. Es la entrada de la Salud Pública en los ambientes y procesos productivos.

El Programa de Salud del Trabajador (PST) de la ciudad de Volta Redonda, localizada en el estado del Río de Janeiro, fue el escenario de donde partieron los análisis, siendo protagonistas del estudio los profesionales que componen el equipo de VST de este Programa. La aproximación al tema enfocó nociones acumuladas en el campo de la Salud del Trabajador (ST), tales como la de salud, trabajo y riesgo, colocándolas en diálogo con aportaciones oriundas de la Psicología del Trabajo Italiana y Francesa, de la Ergonomía de la Actividad, de la perspectiva Ergológica y del planteamiento de la Clínica de la Actividad, especialmente en lo que convergen para el desarrollo de la noción de actividad.

\section{Un proceso de coanálisis y coelaboración de la experiencia : a propósito del dispositivo metodológico de la auto-confrontación cruzada}

El principal dispositivo del cual lanzamos mano fue la auto-confrontación cruzada (Clot, 1999, 2000 ; Faïta, 2005), que tiene como recurso básico, imágenes filmadas de la actividad de trabajo. Manteniendo el foco de la intervención en una situación específica de trabajo, la auto-confrontación cruzada propone al(a los) sujeto(s) la tarea de elucidar para otro, que puede ser tanto el investigador, formador o un colega de trabajo que se ocupa de la misma actividad, y para si mismo, las cuestiones que surgen en el desarrollo de las actividades presentadas, con la ayuda del vídeo.

5 Este dispositivo al conformar diferentes contextos de análisis produjo una considerable pluralidad y riqueza en términos de posibles puntos de vista que se asomaron sobre la actividad. Los protagonistas desempeñaron simultáneamente los papeles de espectadores, personajes, actores, autores y coautores de la actividad de vigilancia y de la actividad de análisis. Dio paso a muchas posibilidades de analizar, comprender, realizar o no realizar en la actividad de VST. Puso en escena la necesidad de articulación con algunos de los conceptos que se presentaron como herramientas 
importantes para el análisis de esa actividad tales como el concepto de genero profesional (Clot, 1999 ; Clot \& Faïta, 2000), y real de la actividad (Clot, 1999 ; 2001), así como el concepto de normas antecedentes (Schwartz, 2000). Observamos que ese dispositivo propició un espacio consistente para elaborar y formalizar la experiencia en la actividad de vigilancia, configurándose como un dispositivo de formación. Esta potencialidad del método en términos de desarrollo de la actividad también fue compartida por nuestros socios en análisis

\section{Actos del trabajo vivo: pistas sobre lo real de la actividad de VST}

Observamos que las prescripciones en esa actividad asumen un carácter amplio y multidefinido, presentándose más con características de Normas Antecedentes, tal como definido por Schwartz (2000).

7 Identificamos que el planteamiento del proceso de trabajo, por los vigilantes, enfoca predominantemente los aspectos físicos, químicos, mecánicos y biológicos de la relación de los sujetos con el trabajo, es decir, el punto de vista de las condiciones de trabajo, colocando en el centro de la vigilancia en salud del trabajador, los agravios, enfermedades y accidentes. Los determinantes son perseguidos a través de parámetros mensurables, con vista a controlarlos o eliminarlos. Esas reflexiones remiten inevitablemente al sentido que viene siendo atribuido a la noción de salud en ese referencial.

8 Contrastando con esa realidad, encontramos uno de los principios básicos que constituyen el campo de la ST, relativo a la importancia y centralidad de los conocimientos oriundos de la experiencia y del punto de vista de los trabajadores. Observamos que ese principio (norma antecedente) aunque eminentemente presente y considerado importante por los vigilantes, parece frágil, careciendo de estrategias de operatividad, pareciendo incluso no encontrar sostenibilidad para ser hacerlo por ellos, durante las acciones.

9 Esa observación envía las características que parecen delinear un genero profesional (Clot, 1999; Clot \& Faïta, 2000) de VST. Entre ellas, una preocupación entre los vigilantes, de buscar respaldar su toma de posición durante las acciones, en bases sólidas e incuestionables. La discusión que proponemos acerca de esos elementos comparece articulada al análisis que hacemos de una dimensión más amplia donde esta práctica se inscribe. Llamamos la atención para lo que consideramos como una fragilidad del respaldo institucional a las acciones de VST, la cual identificamos vinculada a las relaciones capital-trabajo, en la cual operan estos actores. Merece atención el modo como cada uno busca lidiar con la referida fragilidad del respaldo institucional en el curso de la acción y los impactos que esa situación tiene sobre el poder de actuar en ese colectivo. Como ponen a prueba los personajes, desafiándolos a encontrar posibles, a pesar de ella. A tornar la situación vivible. Esa nos pareció, entre tantas otras, una pista importante a perseguir: ¿hasta qué punto, y con qué repercusiones para sus protagonistas, resistirá un género cuyo respaldo institucional es frágil?

10 Al colocar en circulación la noción de inactividad impuesta (Clot, 1999), surgen importantes elaboraciones hechas por los vigilantes sobre las relaciones de poder que 
identifican en el sector público de salud que implican directamente en los márgenes de autonomía en relación a la actividad. Las sucesivas alternancias en la administración pública, por ejemplo, indican posibles impactos a la política municipal de salud del trabajador, y consecuentemente a la salud de aquellos responsabilizados por su ejecución cotidiana.

11 Observamos que aquello que cada uno dice, como lo dice y con quien habla, produce efectos en el transcurso de la acción. Esos efectos se hacen sentir a través de las reacciones de los colegas vigilantes y de la receptividad o no de los trabajadores y de los empleadores. Pensamos que eso tenga implicaciones en la propia eficacia de la acción. Eficacia, que en esta actividad se va diseñando como una eficacia siempre relativa, desde que colocados en perspectiva los diferentes objetivos que se debe, que se pretende, que se desea, que se necesita y que se puede perseguir en su curso.

Esa pista apunta hacia la importancia de la actividad de lenguaje, que es un recurso fundamental en la actividad de vigilancia. Tal como evidenciado por Schwartz (2003) y Clot (1999) pudimos entender que el lenguaje en ese contexto no es apenas un medio de expresión. Ella es una actividad en si misma. Paradojalmente, tal actividad, fundamental en ese oficio, parece encontrarse interdictada. La controversia entre los profesionales que componen el equipo de vigilancia, condición importante de la actividad, que permite renovar y fortalecer el género profesional (Clot, 1999) el debate, las variantes, las creaciones, las confrontaciones, parecen interdictados en ese oficio. Son pistas que nos llevan a pensar en las repercusiones de esta situación para los vigilantes, sobre el poder de actuar sobre si mismos y sobre el medio de trabajo.

Entre los sentidos que se producen, sobre el acto de vigilar, en esta actividad, sobresale aquél que lo asocia a la aplicación de conocimientos ya cristalizados en lo que tañe la prevención de riesgos y comprobación de hipótesis previamente formuladas. Queda en la penumbra el potencial de esa actividad relativa a la producción de conocimientos en el momento mismo de las acciones. Ese aspecto merece atención, puesto que el trabajo de los vigilantes implica la defensa de determinadas posiciones sobre lo que se descubre por ellos en la actividad de vigilancia. Eso significa atentar para la importancia de la construcción de medios que posibiliten elaborar los descubrimientos hechos en la actividad, los cuales no se dejan comprender a través de planteamientos cuantitativos o epidemiológicos. Eso apunta para la necesidad de creación de procedimientos que 'autoricen' esos descubrimientos.

14 Actuando silenciosamente con el saber-hacer de prudencia (Cru \& Dejours, 1983) desarrollado por los vigilantes para hacer frente a la convivencia con los riesgos a su propia salud en el curso de las acciones, sospechamos que estén, en otro extremo involucrado en esa actividad, el saber-hacer de prudencia, de los trabajadores con los cuales los vigilantes interactúan. Esa puede ser una región en la que nuestros diversos personajes parecen encontrarse y desencontrarse en un complejo laberinto. Esperamos que esa investigación contribuya para ampliar las posibilidades de comprender esa actividad y también en la profundización de la reflexión sobre la necesidad de utilizar dispositivos que permitan abrir y transitar por las hendiduras del trabajo vivo, volviéndose hacia la elaboración colectiva de la experiencia de trabajo. Intentar hacerla disponible a la construcción de nuevos modos de hacer y de decir en el cotidiano de las acciones que permitan un enganchamiento singular-colectivo de los protagonistas de modo que el objetivo de promoción de la salud que persiguen para los otros trabajadores esté en sintonía con la promoción de su propia salud. 


\section{BIBLIOGRAFÍA}

Clot, Y. (1999). La fonction psychologique du travail. Paris : PUF.

Clot, Y. (2001).Clinique du travail, clinique du réel. Le journal des psychologues, 185, 48-51.

Clot, Y. \& Faïta, D. (2000).Genres et styles en analyse du travail. Travailler, 4, 7-43.

Cru, D. \& Dejours, C. (1983). Les savoirs-faire de prudence dans lês métiers du bâtiment. Les Cahiers Médico-Sociaux, 3, 239-247.

Faïta, D. (2005). Análise Dialógica da Atividade Profissional. Rio de Janeiro : Imprinta Express.

Jean, R. (2001). Sobre o agir ergológico. Trabalho apresentado no COLÓQUIO ALAIN WISNER E AS TAREFAS DO PRESENTE, 9 e 10 de março de 2001, Université de Provence, INÉDITO (trad. Ana Luiza Telles). Schwartz, Y. (2000). Le paradigme ergologique ou un métier de philosophe. Toulouse : Octarès.

\section{AUTOR}

\section{KÁTIA SANTORUM}

Universidade de Santa Cruz do Sul / RS Rua 28 de Setembro 16 / 701

katiasan@terra.com.br 